DOI: $10.15593 / 24111678 / 2016.02 .03$

УДК 656.131 .2

\author{
М.А. Жидкова \\ Московский автомобильно-дорожный государственный \\ технический университет (МАДИ), Москва, Россия \\ СЛУЖБА ЗАКАЗА ТАКСИ: \\ ПРОБЛЕМЫ И ПЕРСПЕКТИВЫ РАЗВИТИЯ
}

\begin{abstract}
Рассмотрены основные направления и перспективы развития интерактивных служб заказа такси через мобильные приложения и интернет-сайты, поскольку в настоящее время в условиях жесткой конкуренции на рынке таксомоторных перевозок остаются и успешно продолжают работать только те компании, которые смогли должным образом организовать клиентский сервис.

В ходе исследования был проведен сравнительный анализ пяти самых часто используемых мобильных приложений: Яндекс.Такси, Uber, Gett, Wheely и ЕСТ: Вызов такси, имеющих разные бизнес-модели, целевые аудитории, уровень сервиса и стоимость и занимающих, соответственно, различные сегменты данного рынка пассажирских перевозок. Особое внимание при оценке интерактивных сервисов заказа такси было уделено наличию официального разрешения на осуществление таксомоторных перевозок, техническому состоянию и безопасности легковых автомобилей, знанию города водителями, присутствию бюджетных тарифов и возможных скидок, различных способов оплаты поездки и быстрой подаче транспорта клиенту.

На основе данных проведенного анализа были выявлены проблемы в деятельности мобильных сервисов, в частности сдерживание или снижение тарифов на перевозку пассажиров при постоянном росте цен на топливо, а также передача заказов нелегальным перевозчикам. Предложены основные направления развития интерактивных служб заказа такси, доказавших свою эффективность: расширение деятельности в новых крупных и небольших городах, возможность удешевления стоимости поездки за счет подсадки второго пассажира в том же направлении, рост системы предоставляемых скидок и бонусов и возможностей электронной оплаты.

Ключевые слова: такси, легковой таксомоторный транспорт, таксомоторные перевозки, заказ такси, диспетчерская служба, мобильные сервисы, интерактивная служба заказа.
\end{abstract}

\author{
M.A. Zhidkova \\ Moscow State Automobile and Road Technical University, \\ Moscow, Russian Federation

\section{SERVICE OF THE ORDER OF A TAXI: PROBLEMS AND PROSPECTS OF DEVELOPMENT}

In article the main directions and prospects of development of interactive services of the order of a taxi through mobile applications and the Internet sites as now in the conditions of fierce competition in the market of taxi transportations remain are considered and successfully only those companies which could organize client service properly continue to work.

In the course of research the comparative analysis of five most often used mobile applications was carried out: Yandex.The taxi, Uber, Gett, Wheely also eats: a call of the taxi having different business models, target audiences, level of service and cost, and occupying respectively various segments of this market of passenger traffic. 
The special attention at an assessment of interactive services of the order of a taxi was paid to existence of official permission to implementation of taxi transportations, technical condition and safety of cars, knowledge of the city by drivers, presence of the budgetary tariffs and possible discounts, various payment methods of a trip and fast giving of transport to the client.

On the basis of data of the carried-out analysis problems in activity of mobile services, in particular control or reduction of tariffs for transportation of passengers were revealed at a constant increase in prices for fuel, and also transfer of orders to illegal carriers.

The main directions of development of interactive services of the order of the taxi which proved the efficiency were in summary offered: expansion of activity in the new large and small cities, possibility of reduction in cost of cost of a trip due to replanting of the second passenger in the same direction, growth of system of the provided discounts and bonuses and opportunities of electronic payment.

Keywords: taxi, automobile taxi transport, taxi transportations, order of a taxi, dispatching service, mobile services, interactive service of the order.

Развитие современных информационных и телекоммуникационных технологий расширяет возможности каждого человека во всех сферах жизнедеятельности. Инновационный прогресс не обошел стороной услуги такси.

Интерактивные или мобильные сервисы вызова такси являются сравнительно новой услугой, предоставляемой независимыми компаниями. Следовательно, привычный способ заявки - «звонок диспетчеру таксомоторной компании» - теряет свою актуальность [1].

Экономический спад затронул многие отрасли и, в частности, такой сегмент рынка, как предоставление услуг по перевозке пассажиров на такси. В результате сократилось число организаций и индивидуальных предпринимателей, оказывающих данный вид услуг.

Однако в условиях жесткой конкуренции на рынке таксомоторных перевозок остаются и успешно продолжают работать те компании, которые смогли должным образом организовать свой клиентский сервис.

В настоящее время во многих крупных городах России работают мобильные приложения по вызову такси. Установленное в смартфоне приложение позволяет в несколько кликов найти свободный автомобиль и сделать заказ. Среднее время ожидания машины сократилось с 20 мин после телефонного вызова до 5-10 мин.

Первый мобильный сервис такси появился на российском рынке в 2010 году. Яндекс.Такси представил мобильное приложение, интегрированное с собственными картами. Принцип работы с самого основания остается неизменным - собственного таксопарка у сервиса нет, компания выступает посредником, делегируя заказы уже работающим на рынке компаниям [2]. 
В 2012 г. у Яндекс.Такси появился конкурент - GetTaxi, израильский сервис, который был успешно опробован в Тель-Авиве. Его внедрение сопровождалось агрессивной рекламной кампанией и инвестициями в размере 15-20 млн долл.

Успех двух первооткрывателей мобильного сервиса такси в России не оставил равнодушными многих предпринимателей. Постепенно появилось множество конкурентов, каждый из которых попытался занять определенную нишу. Так, иностранные компании Uber и Wheely сделали ставку на сегмент класса люкс, предложив транспортировку клиента на дорогих марках автомобилей.

Как показывает анализ рынка такси (рис. 1), в настоящее время наиболее часто используемыми являются пять приложений: Яндекс.Такси, ЕСТ: Вызов такси, Gett (GetTaxi), Uber и Wheely.

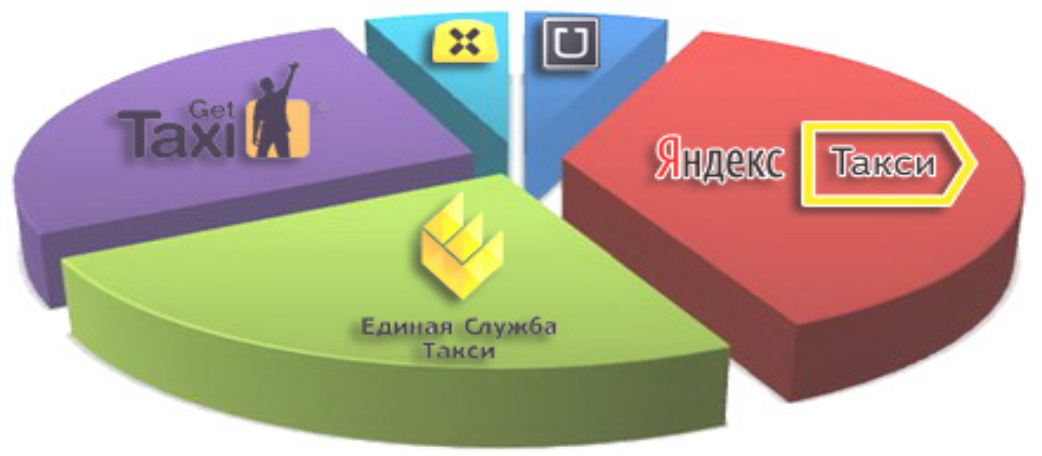

Рис. 1. Структура заказов такси через мобильные приложения [3]

Приведенные сервисы заказа такси имеют разные бизнес-модели, целевые аудитории, уровень сервиса и стоимость [4].

Такси, заказанное через агрегатор, обходится пассажирам дешевле, чем такси из традиционного таксопарка, так как последние вынуждены включать в цену затраты на персонал и амортизацию транспорта, а также выполнять различные требования законодательства, которые, как правило, не касаются агрегаторов и диспетчерских служб.

Яндекс.Такси отличается от других, поскольку является площадкой - агрегатором для лицензированных таксопарков. Ему принадлежит сервис картографии, внушительная база адресов. Он способен выполнить анализ пробок в течение минуты. Движение автомобиля можно отслеживать по карте. Такси приезжают быстро, особенно в столице. 
Следующим в списке числится «ЕСТ: Вызов такси». Данный сервис работает на территории России, соседних государств и дальнего зарубежья. Клиент выбирает автомобиль самостоятельно. В этом поможет рейтинг транспорта, который, кстати, можно дополнить отзывом после поездки. Машина приезжает в течение 20 мин, приложение информирует о ее подаче. Стоимость поездки рассчитывается заранее, расценки вполне демократичные. В «ЕСТ: Вызов такси» предусмотрен бонусный счет каждому клиенту: за каждую поездку - бонус, за каждого приглашенного друга - бонус; накопленными бонусами ими можно оплачивать поездки.

Cервис Gett - главный конкурент Яндекс.Такси. Подача машины оперативная, на территории Москвы и Петербурга - 6-9 мин, отслеживать ее передвижение также можно по электронной карте. Особенность сервиса - расчет времени на обратную поездку, т.е. можно рассчитать полное время в дороге. Каждая машина в идеальном состоянии, в салоне пассажирам доступы бесплатный Wi-Fi и розетки для зарядки телефонов.

Целевые группы заказчиков услуг каждой из служб также значительно отличаются.

Яндекс.Такси позволяет экономить, поскольку использование этого сервиса гораздо дешевле. Кроме того, есть возможность оплатить поездку не только наличными, но и Яндекс.Деньгами или банковской картой. Поэтому Яндекс.Такси получил сегмент экономкласса [5].

Клиенты с более высокими требованиями тоже часто пользуются этим мобильным сервисом - их привлекает предсказуемость: марка машины и наличие дополнительных опций известно заранее. Но все же большую часть бизнес-класса привлек к себе Gett. Более строгие требования к автопарку компании-партнера, собеседование с водителями при заключении контракта, рейтинговая система делает обслуживание практически безупречным. Платить за поездку можно как наличными, так и картой.

Очевидно, что основными преимуществами Яндекс.Такси являются десятки компаний-сотрудников, элементарный ввод начальной и конечной точки и возможность оплаты любым удобным способом.

Быстрый вызов машины, информирование клиента о подаче транспорта, доступные цены, рейтинг автомобилей, обширная география работы и бонусы за поездки - преимущества приложения «ЕСТ: вызов такси». 
Обратимся к преимуществам Gett. К ним можно отнести идеальное состояние автомобилей - такси, отличное знание города водителями, присутствие бюджетных тарифов и быструю подачу транспорта [6].

Рассмотрим другие мобильные сервисы.

Uber - это не такси, а служба подачи машин с водителем. Основные отличия здесь заключаются в отсутствии лицензии и наличии у машин сервиса - обычных, а не желтых номеров, что не дает им возможности заезжать на полосы для общественного транспорта.

Цена здесь складывается из стоимости посадки, а также платы за каждую минуту и за каждый километр. Платить в Uber можно только картой, деньги снимаются автоматически в конце поездки. Туда же можно включить и чаевые. Цены меняются динамично - в зависимости от загрузки службы. Машин пока не очень много, и своих клиентов водители предпочитают дожидаться в центре города - там время подачи держится на уровне 5-10 мин. В спальных же районах свободных автомобилей может не оказаться вовсе.

Следует отметить, что в 2015 г. между правительством Москвы и сервисами по заказу такси Яндекс.Такси, Uber и Gett были достигнуты соглашения о том, что компании-агрегаторы будут привлекать к работе только легальных таксистов, которые получили разрешение на деятельность. Эти соглашения необходимы для обеспечения безопасности пассажиров, так как водитель, получивший разрешение на осуществление таксомоторной деятельности, соответствует определенным требованиям [7].

Использование легальной службы такси, оформленной в соответствии с законодательством, в теории гарантирует клиенту полную безопасность поездки. На практике многое также зависит и от специфики работы компании-перевозчика. На данный момент московские власти делают все возможное, чтобы столичное такси было удобным и доступным средством. Важным элементом реформы рынка таксомоторных услуг стало предоставление дополнительных преференций легальным перевозчикам, установление обязательных требований к таксистам, к состоянию автомобилей и борьба с нелегальными перевозчиками.

Обратимся к деятельности и других мобильных сервисов такси.

B действительности Wheely - тоже не такси, а служба вызова машины с водителем. Сервис достаточно дорогой, короткая поездка обойдется в 400 руб., причем этого хватит всего на 10 мин поездки. 
B 2014 г. Wheely усложнили свою схему, добавив к поминутной тарификации еще и плату за километраж.

Машин у Wheely не очень много, и чем выше класс, тем дольше придется ждать. В центре города автомобиль в загруженные часы приедет лишь через 10-15 мин. Платить можно только картой, сервис взял за правило не работать с наличностью [8].

При анализе рынка таксомоторных перевозок нельзя обойти вниманием inTaxi и CityMobil.

Агрегатор inTaxi тоже работает со множеством таксопарков, но использует их исключительно как подрядчиков для исполнения заказов, а общается с клиентами и решает все проблемы исключительно от своего имени [9].

Цена всегда едина и меняется только в зависимости от времени суток. К сожалению, платить пока можно только наличными или бонусами, которые накапливаются с каждой поездкой. Из дополнительных опций есть только «некурящий водитель», кондиционер и детское кресло.

Для машин бизнес-класса не предусмотрен отдельный тариф, вместо этого к сумме прибавляются 200 руб.

Диспетчерская CityMobil вовремя ощутила веяние новых технологий, и теперь ее можно сравнивать с самыми крупными игроками на рынке такси. Заслуга в этом не только водителей, но и удобного мобильного приложения. При заказе можно запросить «некурящего водителя» или, напротив, машину, в которой разрешается курить, детское кресло, кондиционер. Отдельная опция - желтые номера.

Для обобщения проведенного анализа мобильных сервисов такси сведем результаты в таблицу.

Из данных, приведенных в таблице, видно, что тарифы нелинейны и включают разную плату за посадку и разную цену минуты и километра поездки.

На первый взгляд, тарифы мобильных сервисов различаются не сильно. Яндекс.Такси установил гарантированную цену в 199 руб. за первые 10 мин поездки, после чего тарификация идет по формуле 14 руб. в минуту. Ночью к этому прибавляется 7 руб. за каждый километр [10].

У Uber похожая форма расчета, но без учета времени суток: 8 руб. за каждую минуту пути и 8 руб. за каждый километр. Gett имеет caмую простую формулу из всех - 18 руб. за каждую минуту поездки [11]. 


\begin{tabular}{|c|c|c|c|c|c|c|c|c|c|c|c|}
\hline 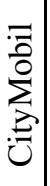 & 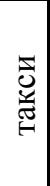 & 舀 & 采 & 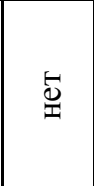 & $\underset{\square}{\varpi}$ & 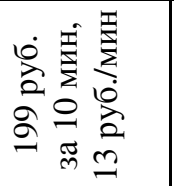 & 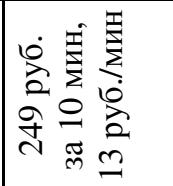 & $\underset{\nabla}{\sigma}$ & $\tilde{\pi}$ & 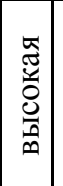 & 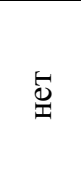 \\
\hline 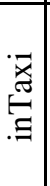 & 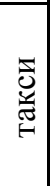 & ש & $\stackrel{\pi}{\sigma}$ & $\stackrel{్}{0}$ & $\tilde{\sigma}$ & 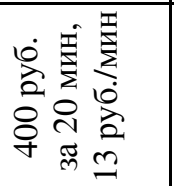 & 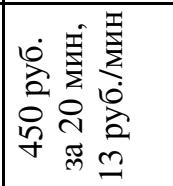 & $\underset{\sigma}{\sigma}$ & $\underset{\mathbb{T}}{\vec{⿹}}$ & 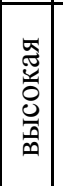 & 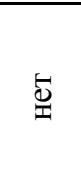 \\
\hline $\begin{array}{l}\frac{\lambda}{d} \\
\stackrel{d}{3}\end{array}$ & 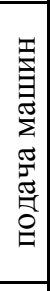 & ש & 䨔 & ש & $\stackrel{\tilde{\sigma}}{\pi}$ & 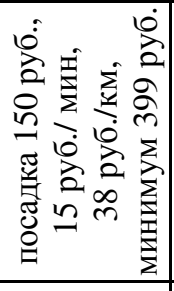 & 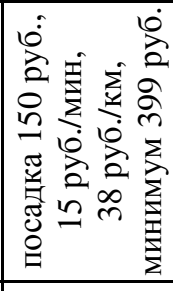 & $\stackrel{\vec{⿹}}{\vec{x}}$ & $\tilde{\sigma}$ & 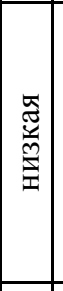 & 满 \\
\hline $\begin{array}{l}\underset{\bar{d}}{\Delta} \\
\dot{D}\end{array}$ & 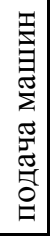 & $\stackrel{\pi}{\pi}$ & 采 & ש & 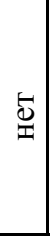 & 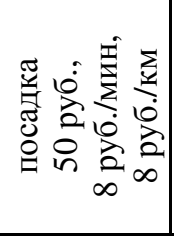 & 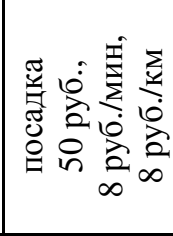 & $\stackrel{\sqrt[্]{x}}{\vec{x}}$ & 采 & 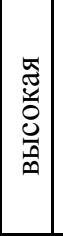 & $\underset{]}{\stackrel{⿹}{]}}$ \\
\hline 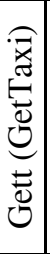 & 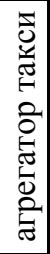 & $\stackrel{\pi}{\pi}$ & $\stackrel{\tilde{\sigma}}{\tilde{\sigma}}$ & $\stackrel{\overrightarrow{0}}{\underline{x}}$ & $\stackrel{\widetilde{\sigma}}{\tilde{E}}$ & 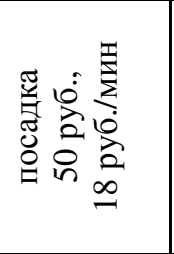 & 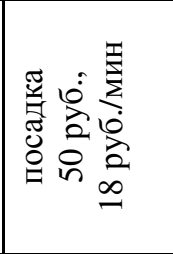 & $\underset{\nabla}{\sigma}$ & $\underset{E}{\pi}$ & 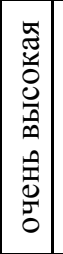 & שี \\
\hline 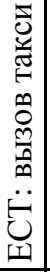 & 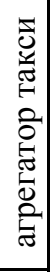 & 舀 & $\tilde{\sigma}$ & ש & $\stackrel{\widetilde{\sigma}}{\tilde{E}}$ & 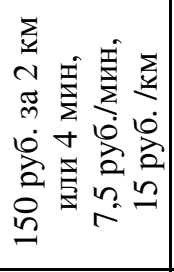 & 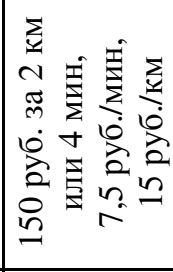 & $\underset{\nabla}{\sigma}$ & $\underset{\Xi}{\Xi}$ & 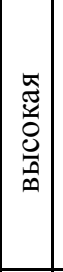 & 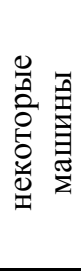 \\
\hline 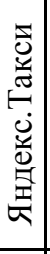 & 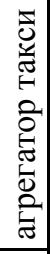 & $\stackrel{\tilde{E}}{\tilde{E}}$ & 孚 & ש & $\tilde{\sigma}$ & 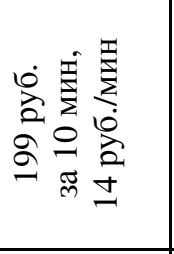 & 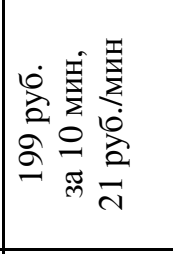 & $\underset{\sigma}{\sigma}$ & $\stackrel{\tilde{\sigma}}{\tilde{T}}$ & 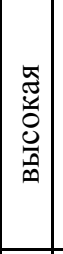 & 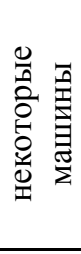 \\
\hline 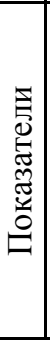 & 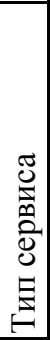 & 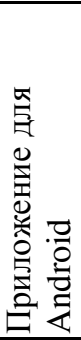 & 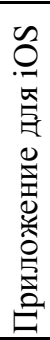 & 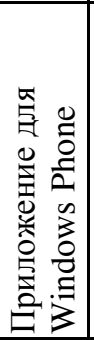 & 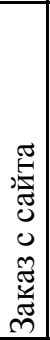 & 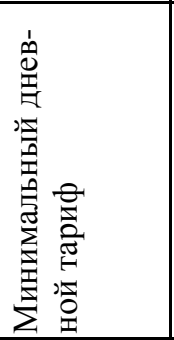 & 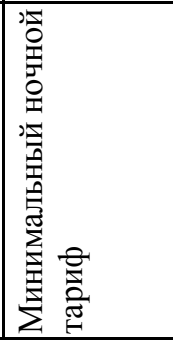 & 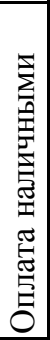 & 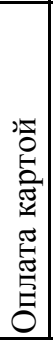 & 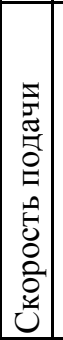 & 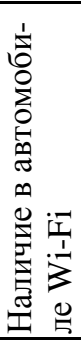 \\
\hline
\end{tabular}


Для того чтобы определить, какой сервис такси будет дешевле, приведем графики (рис. 2, 3). Расчет стоимости поездки на такси производился при условии, что средняя скорость движения автомобилей в Москве: 24 км/ч днем и 42 км/ч ночью.

Следует отметить, что начиная с 2016 г., все московские официальные такси получили право передвижения по выделенным полосам, что позволит увеличить их среднюю скорость до 38 км/ч. С выделенных для общественного транспорта полос в Москве демонтированы знаки «Въезд запрещен». Это позволило всем обладателям разрешений на таксомоторную деятельность передвигаться по выделенным полосам для общественного транспорта. Для пассажиров такси возможность передвижения по выделенным полосам означает сокращение времени и стоимости поездки.

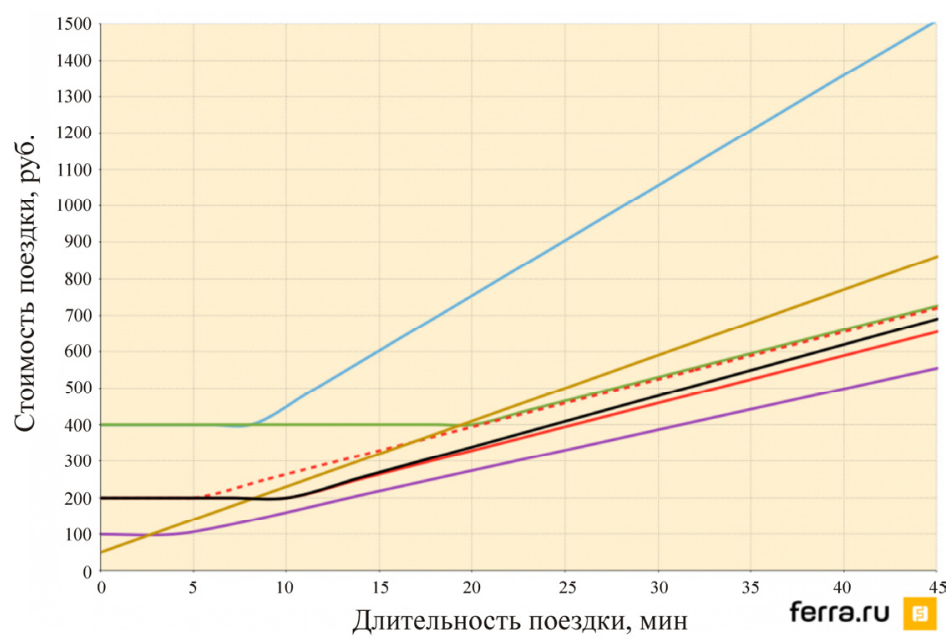

Рис. 2. Средняя стоимость дневной поездки на такси в Москве [12]:

-Яндекс.Такси; - GetTaxi; - UberX; -- CityMobil (до 12 января); - CityMobil (после 12 января); - inTaxi; - Wheely

Как показали расчеты, наиболее дешевый вариант поездки предоставляет UberX. Средняя цена за километр пути у этого сервиса составила чуть больше 23 руб. У конкурентов этот показатель сильно выше - 32 руб. у Яндекс.Такси и 35 руб. у Gett. Сервис UberX оказался самым дешевым для поездки любой длительности от 3 мин. Яндекс.Такси и CityMobil идут почти вровень, но, разумеется, не стоит забывать о скорости подачи машины (выше в Яндекс.Такси) и предсказуемости качества (выше у CityMobil). А вот GetTaxi в поездках дольше 20 мин оказался самым дорогим в экономклассе. 


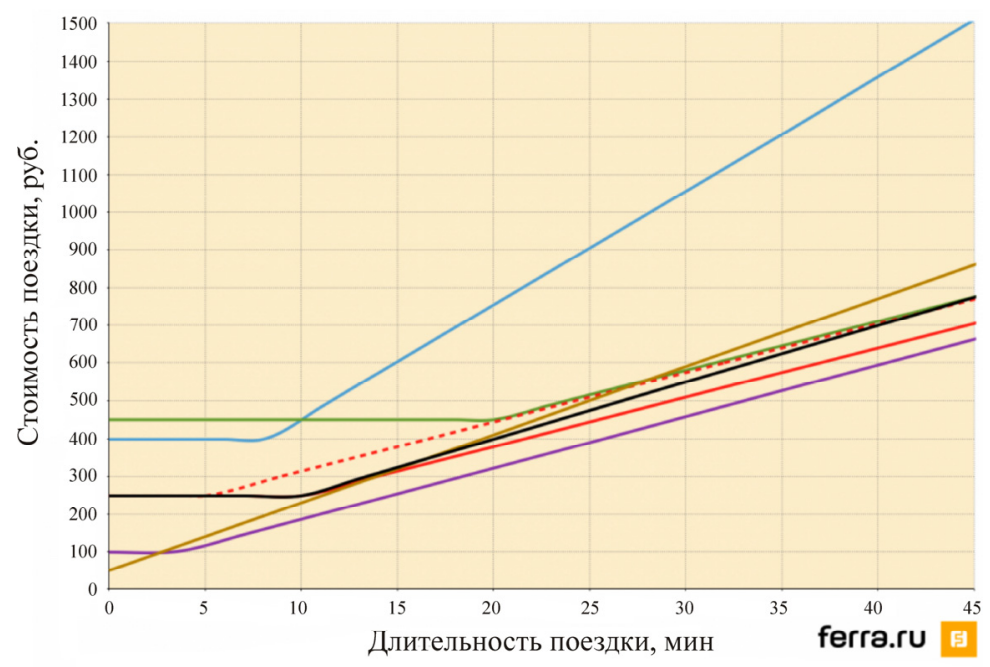

Рис. 3. Средняя стоимость ночной поездки на такси в Москве [12]:

-Яндекс.Такси; - GetTaxi; - UberX; -. CityMobil (до 12 января); -CityMobil (после 12 января); - inTaxi; - Wheely

Для ночных поездок с ограниченным бюджетом оптимальным вариантом также стал UberX. Поездка продолжительностью 20-25 мин у всех конкурентов, кроме Wheely, обойдется примерно в одну и ту же цену. Только inTaxi выглядит невыгодным при поездках до 20 мин.

Средняя цена проезда в такси ежегодно увеличивается. Основным фактором роста показателя стало увеличение цен на бензин. Также дополнительные издержки накладывают процедура легализации бизнеса, привлечение квалифицированных водителей и обновление парка автомобилей. Сдерживающее влияние на рост цен оказывает усиление конкуренции на рынке за счет появления мобильных приложений и интернет-сервисов, с помощью которых можно выбрать наиболее привлекательные по цене услуги [13].

За последние 5 лет число поездок на такси в стране увеличилось на 30,1 \%: с 168,6 до 219,4 млн поездок. Основным фактором роста данного показателя стало технологическое развитие отрасли: внедрение мобильных сервисов в деятельность такси [14].

В последнее время сервисы все активнее конкурируют между собой. В начале июня 2015 г. Gett анонсировал новый тариф Sale, который предлагает скидку в 30 \% на дневные поездки. Спустя месяц Uber сообщил о снижении цен на трансфер в аэропорты для жителей столицы до 1000 руб., а Яндекс.Такси подключил к системе два электромо- 
биля Tesla, которые теперь доступны жителям столицы наряду с остальными машинами.

На сегодняшний день что интерактивный сервис заказа такси доступен только в крупных городах, поэтому перспективы роста очевидны. Мобильные приложения по вызову такси уже доказали свою эффективность, теперь дело за совершенствованием сервиса и за охватом новых крупных и небольших городов. Специалисты предсказывают, что через 10 лет онлайн-вызовы практически вытеснят диспетчерские службы такси [15].

В перспективе появление новых, еще более привлекательных видов услуг. Это возможность удешевления поездки за счет подсадки второго пассажира в том же направлении, развитие системы скидок и бонусов, расширение возможностей электронной оплаты.

Проведенное исследование мобильных сервисов заказа такси позволяет сделать следующие выводы:

1. За последние несколько лет крупные таксопарки начали предоставлять услугу онлайн-заказа машины, которая со временем из вебсервиса превратилась в мобильные приложения.

2. Интерактивные службы позволяют оптимизировать работу таксомоторных компаний и индивидуальных предпринимателей, улучшать взаимодействие водителей и диспетчеров, предотвращать чрезвычайные ситуации, контролировать процесс, оперативно управлять базой данных клиентов.

3. Сравнение основных агрегаторов такси, действующих в Москве, показало, что самый комфортный вариант для езды - это Wheely, а самым оптимальным вариантом - быстрым, дешевым и качественным сейчас является Uber X.

\section{Список литературы}

1. Таксомоторные войны: мобильные сервисы против таксопарков [Электронный ресурс]. - URL: http://tass.ru/obschestvo/2095730 (дата обращения: 20.03.2016).

2. Большой обзор сервисов для заказа такси в Москве [Электронный ресурс]. - URL: http://playittodeath.ru/obzor-servisov-dlya-zakazataksi-v-moskve/ (дата обращения: 20.03.2016).

3. Мобильные приложения такси [Электронный ресурс]. - URL: https://taxif1.ru/taxi-app (дата обращения: 20.03.2016). 
4. Жидкова М.А. Анализ и перспективы развития мобильных сервисов на рынке таксомоторных перевозок // Автотранспортное предприятие. - 2016. - № 3. - С. 3-6.

5. Обзор интерактивных сервисов вызова такси [Электронный pecypc]. - URL: http://reiting-taksi.ru/novosti/obzor-servisov-vyzova-taksi/ (дата обращения: 20.03.2016).

6. Проблемы такси и их решение [Электронный ресурс]. - URL: http://taxi-capital.ru/Taksi-onlajn-v-Moskve/problemy-taksi-i-ih-reshenie.php (дата обращения: 20.03.2016).

7. Официальный сайт Департамента транспорта и развития дорожно-транспортной инфраструктуры города Москвы: Таксомоторная деятельность. - URL: http://dt.mos.ru/projects/the-taxi-activity/ (дата обращения: 20.03.2016).

8. Стартаперы представили мобильный агрегатор всех сервисов такси [Электронный ресурс]. - URL: http://adindex.ru/news/digital/2015/ 12/23/130996.phtml (дата обращения: 20.03.2016).

9. Проблемы такси и таксомоторных перевозок [Электронный pecypc]. - URL: http://www.km.ru/category/tegi/taksi-v-moskve (дата обращения: 20.03.2016).

10. Глазунов А. Кто дешевле Uber, Gett или Яндекс-Такси - сравнение мобильных сервисов такси в Санкт-Петербурге и Москве [Электронный ресурс]. - URL: http://www.life-in-travels.ru/2015/12/sravnenieuber-gett-yandex-taxi.html (дата обращения: 20.03.2016).

11. Баев А. Тест для такси [Электронный ресурс]. - URL: http://rbcdaily.ru/industry/562949996204399 (дата обращения: 20.03.2016).

12. Рубцов И. Мобильное такси. Полное сравнение сервисов вызова такси (январь 2015) [Электронный ресурс]. - URL: http:// www.ferra.ru/ru/mobile/review/mobile-taxi-jan-2015/\#.VqzNfdFumUk (дата обращения: 20.03.2016).

13. Анастасов М.С. Подходы и методы сбалансированного развития экономических систем // Инновационная экономика: информация, аналитика, прогнозы. - 2013. - № 1-2. - С. 5-7.

14. Новые рынки: мобильные сервисы для такси [Электронный pecypc]. - URL: http://svdelo.ru/zhurnal/zhurnal-svoe-delo-novye-rynkimobilnye-servisy-dlya-taksi (дата обращения: 20.03.2016).

15. Официальный сайт Российско-Американской академии бизнеса такси. - URL: http://taxiacademy.ru/ (дата обращения: 20.03.2016). 


\section{References}

1. Taksomotornye voiny: mobil'nye servisy protiv taksoparkov [Taxi wars: mobile services against taxi pools], available at: http://tass.ru/ obschestvo/2095730 (accessed 20 March 2016).

2. Bol'shoi obzor servisov dlia zakaza taksi v Moskve [The big review of services for the order of a taxi in Moscow], available at: http://playittodeath.ru/obzor-servisov-dlya-zakaza-taksi-v-moskve/ accessed 20 March 2016).

3. Mobil'nye prilozheniia taksi [Mobile applications of a taxi], available at: https://taxif1.ru/taxi-app (accessed 20 March 2016).

4. Zhidkova M.A. Analiz i perspektivy razvitiia mobil'nykh servisov na rynke taksomotornykh perevozok [The analysis and prospects of development of mobile services in the market of taxi transportations]. Avtotransportnoe predpriiatie, 2016, no. 3, pp. 3-6.

5. Obzor interaktivnykh servisov vyzova taksi [Review of interactive services of a call of a taxi], available at: http://reiting-taksi.ru/novosti/obzorservisov-vyzova-taksi/ (accessed 20 March 2016).

6. Problemy taksi i ikh reshenie [Problems of a taxi and their decision], available at: http://taxi-capital.ru/Taksi-onlajn-v-Moskve/problemytaksi-i-ih-reshenie.php (accessed 20 March 2016).

7. Ofitsial'nyi sait Departamenta transporta i razvitiia dorozhnotransportnoi infrastruktury goroda Moskvy: Taksomotornaia deiatel'nost' [Official site of Department of transport and development of road and transport infrastructure of the city of Moscow: Taxi activity], available at: http://dt.mos.ru/projects/the-taxi-activity/ (accessed 20 March 2016).

8. Startapery predstavili mobil'nyi agregator vsekh servisov taksi [Startups presented the mobile aggregator of all services of a taxi], available at: http://adindex.ru/news/digital/2015/12/23/130996.phtml (accessed 20 March 2016).

9. Problemy taksi i taksomotornykh perevozok [Problems of a taxi and taxi transportations], available at: http://www.km.ru/category/tegi/taksiv-moskve (accessed 20 March 2016).

10. Glazunov A. Kto deshevle Uber, Gett ili Iandeks.Taksi - sravnenie mobil'nykh servisov taksi v Sankt-Peterburge i Moskve [What is cheaper than Uber, Gett or Yandeks-Taksi - Comparison of mobile services of a taxi in St.Petersburg and Moscow], available at: http://www.life-in-travels.ru/ 2015/12/sravnenie-uber-gett-yandex-taxi.html (accessed 20 March 2016). 
11. Baev A. Test dlia taksi [The test for a taxi], available at: http://rbcdaily.ru/industry/562949996204399 (accessed 20 March 2016).

12. Rubtsov I. Mobil'noe taksi. Polnoe sravnenie servisov vyzova taksi (ianvar' 2015) [Full comparison of services of a call of a taxi (January, 2015)], available at: http://www.ferra.ru/ru/mobile/review/mobile-taxi-jan2015/\#.VqzNfdFumUk (accessed 20 March 2016).

13. Anastasov M.S. Podkhody i metody sbalansirovannogo razvitiia ekonomicheskikh system [Approaches and methods of the balanced development of economic systems]. Innovatsionnaia ekonomika: informatsiia, analitika, prognozy, 2013, no. 1-2, pp. 5-7.

14. Novye rynki: mobil'nye servisy dlia taksi [New markets: mobile services for a taxi], available at: http://svdelo.ru/zhurnal/zhurnal-svoe-delonovye-rynki-mobilnye-servisy-dlya-taksi (accessed 20 March 2016).

15. Ofitsial'nyi sait Rossiisko-Amerikanskoi akademii biznesa taksi [The official site of the Russian-American Academy of Business of the Taxi], available at: http://taxiacademy.ru/ (accessed 20 March 2016).

Получено 26.04.2016

\section{Об авторе}

Жидкова Маргарита Анатольевна (Москва, Россия) - кандидат экономических наук, доцент кафедры «Финансы» Московского автомобильно-дорожного государственного технического университета (МАДИ) (125319, г. Москва, Ленинградский пр., 64, e-mail: zhidkova_m_a@madi.ru).

\section{About the author}

Margarita A. Zhidkova (Moscow, Russian Federation) - Ph.D. in Economic Sciences, Associate Professor, Department of Finance, Moscow State Automobile and Road Technical University (64, Leningradskii av., Moscow, 125319, Russian Federation, e-mail: zhidkova_m_a@madi.ru). 